\title{
The regulation of competition and procurement in the National Health Service 2015-2018: enduring hierarchical control and the limits of juridification - ADDENDUM
}

\author{
Dorota Osipovič, Pauline Allen, Marie Sanderson, Valerie Moran and Kath Checkland
}

(First published online 29 October 2019)

https://doi.org/10.1017/S1744133119000240, Published online by Cambridge University Press, 6 September 2019

Keywords: Competition; health care; hierarchy; juridification; market; regulation; addendum

This article when published neglected to mention Dr Valerie Moran's second affiliation. She is affiliated with the Luxembourg Institute of Health, Strassen, Luxembourg and the Luxembourg Institute of Socio-Economic Research, Esch-sur-Alzette, Luxembourg.

\section{Reference}

Osipovič D, Allen P, Sanderson M, Moran V and Checkland K (2019) The regulation of competition and procurement in the National Health Service 2015-2018: enduring hierarchical control and the limits of juridification. Health Economics, Policy and Law 1-17. doi: 10.1017/S1744133119000240.

Cite this article: Osipovič D, Allen P, Sanderson M, Moran V, Checkland K (2020). The regulation of competition and procurement in the National Health Service 2015-2018: enduring hierarchical control and the limits of juridification ADDENDUM. Health Economics, Policy and Law 15, 416-416. https://doi.org/10.1017/S1744133119000264

(c) Cambridge University Press 2019. This is an Open Access article, distributed under the terms of the Creative Commons Attribution licence (http://creativecommons.org/licenses/by/4.0/), which permits unrestricted re-use, distribution, and reproduction in any medium, provided the original work is properly cited. 